\title{
Self-Starter Company President Produces Materials Software
}

\author{
Anjali Nandedkar
}

What do you do after finishing graduate school? You find suitable work that you like. This sounds straightforward as you find a position, work hard, and (hopefully) start climbing a ladder to someday become a head honcho of some large company or institute. I chose a different path. I started a company, declared myself to be the president, and now work to make the company big.

Starting my own company fit most of my priorities well:

Priority \# 1: Flexibility in work schedule. As parents of two young children, my husband and I wanted enough flexibility to care for the children ourselves.

Priority \# 2: Challenging work. I have no problem acquiring diverse and rewarding work since I design the projects and give them to myself.

Priority \# 3: Enough income to run a business and make a living. Generating enough income can be tough sometimes. After spending 12 years in engineering colleges and graduating with all those nifty skills, I realized that I have enough skills to make brilliant products, including software, but I have no knowledge of how to sell or market them. So on-the-job training prevails at the moment. I am happy to be making progress every year and currently have customers in five countries (United States, Canada, Sweden, India, and Japan). The learning process on sales and marketing continues mostly through reading books, but also by systematically trying out various methods, and by discussions with other small business owners.

Priority \# 4: Be my own boss. Sometimes I have a very tough boss and a very lazy employee.

Priority \# 5: A work place with a pleasant atmosphere. When you own the company, you can put your main office anywhere you want, even in your own home. You can assign a detached room or basement as an office; install telephone lines; hook up to the Internet; access Compuserve (for its good technical databases); buy a computer, printer, and fax machine, and you are in business. When you need to meet a prospect, you can rent a conference room for a few hours in a business building downtown. Right now I have a great office mate: our dog, Data. I do miss interacting with people on a daily basis. My contacts are mostly through e-mail, fax, phone, websites, and chat rooms, plus a few times a month I drive a few

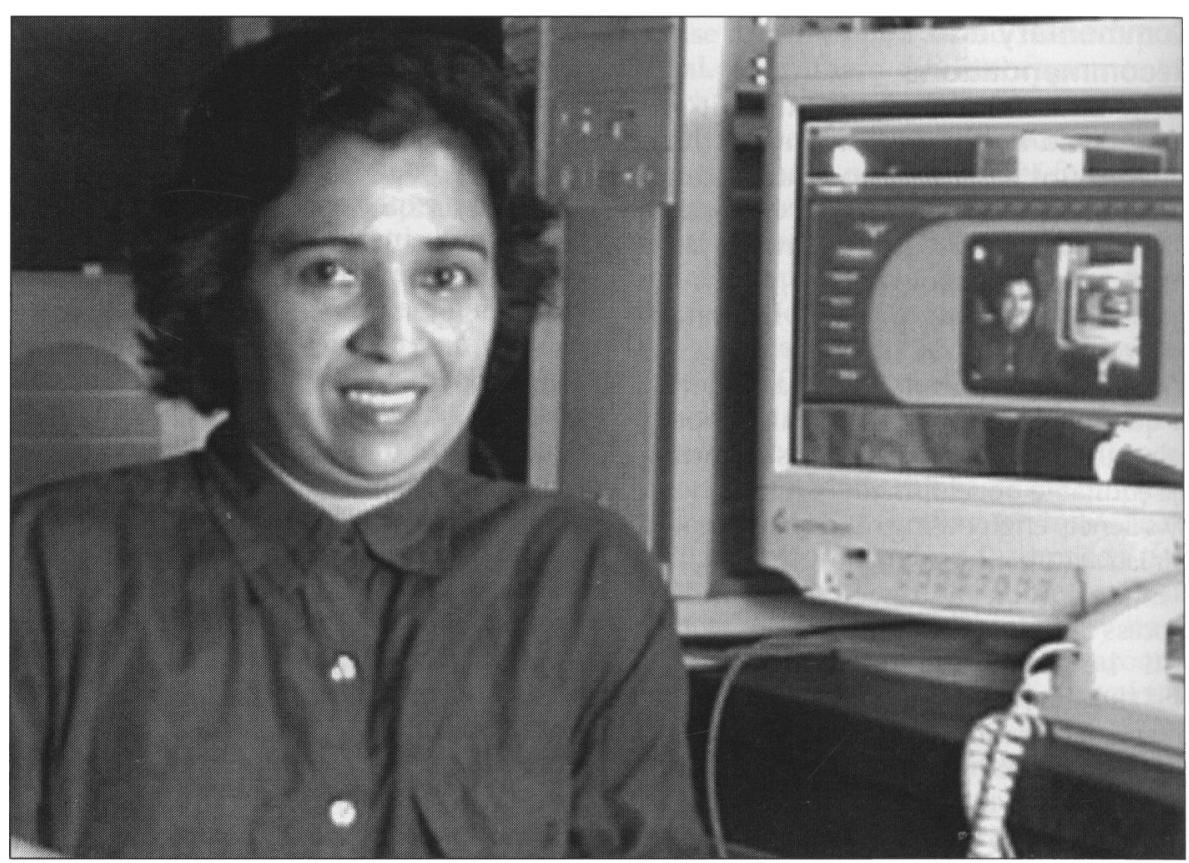

Anjali Nandedkar, president of CASA Engineering (http.//www.casaengineering.com/), produces a software package called ADESH (Atomistic DEfect Simulation Handler) to control defects in materials.

hours to meet prospects and give a presentation demo.

All things considered, I like the advantages of this career more than I dislike the disadvantages.

I am president of CASA Engineering for which I create and sell a software package called ADESH (Atomistic DEfect Simulation Handler) to industries, universities, and research institutes. Providing services to control defects in materials allows me to work on a contract basis with various industries. Metals (metallic bonding), electronic materials (covalent bonding), and ceramics (ionic bonding) cover most materials used in industries. It is a pleasure to work with all of them year after year.

My work involves investigating defect formation processes in all materials at the atomistic level. Understanding nucleation is the goal and atomistic simulation is a powerful tool to achieve that goal. Even high resolution transmission electron

Career Clips explores the range of career possibilities in, or related to, materials science. microscopy requires samples to be at least 50-100 $\AA$ thick. The nuclei of defects are often smaller than $100 \AA$ and hence cannot be observed directly. Therefore, simulation works efficiently.

Defect control work comprises a satisfying blend of research and practical applications. This type of work needs to be done independently to obtain a full perspective on the factors that affect the formation of structural defects in materials. That is where a stand-alone company like mine is indispensable.

In order to achieve the desired technical results, I work as a materials engineer, materials characterization technician, and software engineer. To keep the business running and contact new prospective customers, I create and maintain a website (http:/ / www.casaengineering.com/), use Internet options, design brochures, and follow up on leads.

I have lived and worked in Asia, North America, and Europe so far. The fortunate aspect of materials science is that materials characteristics are identical everywhere on this planet. I wonder if Mars has materials similar to our Earth. 